19 Revue d'histoire du XIXe siècle

Société d'histoire de la révolution de 1848 et des

révolutions du XIXe siècle

$39 \mid 2009$

Le monde de l'imprimé: des territoires aux acteurs -

Education et politique - Histoires politiques

\title{
Karl JACOBY, Shadows at dawn. A Borderlands \\ Massacre and the Violence of History
}

New York/London, Penguin, 2008, 358 p. ISBN : 978-1-59420-193-6.

32,95 dollars.

Tangi Villerbu

\section{CpenEdition}

\section{Journals}

Édition électronique

URL : http://journals.openedition.org/rh19/3977

DOI : 10.4000/rh19.3977

ISSN : $1777-5329$

Éditeur

La Société de 1848

Édition imprimée

Date de publication : 10 décembre 2009

Pagination : 193-195

ISSN : 1265-1354

Référence électronique

Tangi Villerbu, "Karl JACOBY, Shadows at dawn. A Borderlands Massacre and the Violence of History », Revue d'histoire du XIXe siècle [En ligne], 39 | 2009, mis en ligne le 26 mars 2010, consulté le 22 septembre 2020. URL : http://journals.openedition.org/rh19/3977 ; DOI : https://doi.org/10.4000/ rh19.3977

Ce document a été généré automatiquement le 22 septembre 2020.

Tous droits réservés 


\section{Karl JACOBY, Shadows at dawn. A Borderlands Massacre and the Violence of History}

New York/London, Penguin, 2008, 358 p. ISBN : 978-1-59420-193-6. 32,95 dollars.

Tangi Villerbu

1 Avec ce nouvel ouvrage ${ }^{1}$, Karl Jacoby veut, à deux titres, inventer de nouvelles manières de faire de l'histoire. D'un point de vue de la communication de la recherche d'abord, en associant à son livre un site internet offrant une très large gamme de documents, une partie des sources utiles à l'écriture du livre; l'objet se veut pédagogique, il s'agit d'offrir un outil de vulgarisation, certes, mais aussi de travail pour d'éventuels étudiants ${ }^{2}$. En mettant à nu ses sources, l'historien expose ainsi son travail d'interprétation du corpus. Il innove, d'autre part, d'un point de vue de la construction d'un récit de l'Ouest. Cela fait maintenant près d'un quart de siècle que la Nouvelle Histoire de l'Ouest a lancé un vaste chantier sur les modes d'écriture de cette histoire, et l'onction donnée en préface par Patricia N. Limerick, la promotrice première de cette nouvelle histoire ${ }^{3}$, signale assez que nous sommes là en face d'une réponse originale donnée à un problème désormais déjà ancien mais toujours non résolu : comment narrer l'Ouest sans en passer prioritairement par la voix des conquérants?

2 Karl Jacoby a opté pour une voie dont il dit lui-même combien d'inconvénients elle recèle puisqu'en l'empruntant l'historien refuse obstinément la synthèse, comme s'il fallait renoncer à établir un récit unifié du passé. Karl Jacoby s'empare d'un événement singulier : le massacre de Camp Grant le 30 avril 1871. Dans ce coin d'Arizona devenu américain en 1853 seulement, une troupe disparate d'o'odhams, de Mexicains et d'Anglo-Américains a au petit matin massacré des Apaches qui s'étaient mis sous la protection de l'armée, faisant près de 150 morts, dont beaucoup de femmes et d'enfants. Mais le récit de l'événement lui-même n'occupe que les quelques pages initiales de l'ouvrage. L'essentiel réside dans le récit à quatre voix que construit l'historien. En effet ce sont les chemins qui mènent au massacre, et ceux de la 
construction de sa mémoire, qui sont les véritables objets de l'étude, et ces chemins sont reconstitués de manière fragmentée, en fonction des quatre groupes acteurs du drame : les Tohono O'odhams (appelés Papagos ou Pimas par les colons du XIX ${ }^{\mathrm{e}}$ siècle), les Vecinos (les habitants d'origine mexicaine), les Américains, et les Nnee (c'est-à-dire les Apaches). Karl Jacoby veut redonner à chacun le nom qu'il se donnait, ce qui suppose un passage par les langues indiennes (un lexique est fourni) et par l'espagnol.

En montrant comment chacune des trois premières communautés en est venue à s'allier momentanément aux autres contre la quatrième, Karl Jacoby veut démonter la construction des identités dans l'Ouest, et révéler l'épaisseur temporelle qui seule peut expliquer, hors les causes accidentelles ou les prétextes ponctuels de l'affaire de Camp Grant, l'installation sur la longue durée d'une extrême violence dans les rapports sociaux qui caractériserait l'histoire de l'Ouest, et d'une violence souvent, comme ici, organisée publiquement (il y eut des réunions préparatoires au massacre, en présence des notables et élus de Tucson) voire ritualisée. Mais l'élaboration de récits parallèles, si elle permet de dévoiler les ressorts d'une histoire de communautés - ainsi des Vecinos de la région de Tucson, dominants longtemps encore après que la région soit passée sous souveraineté américaine, mais qui après le massacre, et surtout à partir des années 1880 , se voient marginalisés et spoliés à leur tour - empêche trop fréquemment une étude des croisements entre ces groupes, qui apparaissent comme figés, artificiellement objectivés. La complexité de certains itinéraires individuels passe alors au second plan, alors qu'ils transcendent les récits communautaires. Ainsi au fil du récit de Karl Jacoby apparaissent des enfants d'une communauté enlevés par une autre et dont le sort demeure comme entre parenthèse, comme celui des nombreux métis produits par l'histoire du Sud-Ouest en général. D'autre part le facteur religieux aurait pu trouver ici une place plus importante. D'abord parce qu'on s'interroge sur le rôle des prêtres (tous français au demeurant, ce qui ajouterait à la complexité et est traité trop rapidement) et des pasteurs dans cette histoire, puisque la violence ne pouvait pas leur échapper, et que le massacre de Camp Grant, lors de sa préparation comme lors du procès auquel il a donné lieu - tous les accusés furent acquittés - a dû susciter chez eux des réactions ; d'autre part parce que l'idée d'éventuels ressorts religieux au fondement de cette ritualisation de l'usage de la violence mériterait d'être approfondie.

Malgré tout, Karl Jacoby livre un ouvrage important et fascinant, qui est à inscrire dans l'efflorescence actuelle de travaux en histoire de l'Arizona, comme si cet État faisait figure de laboratoire de l'expérience américaine envisagée sous l'angle de l'élaboration des logiques ethniques ou raciales dans des logiques transfrontalières. La plupart des travaux portent sur les décennies qui encadrent 1900, sur l'univers des mines, sur les conflits du travail, alors que les Mexicains sont à ce moment surtout des migrants de fraîche date et que des Européens se sont installés en nombre ${ }^{4}$. Karl Jacoby revient pour sa part sur l'amont du processus et en cherche les racines lorsque les Anglo-Américains surimposent peu à peu leurs propres modèles à ceux qui leur préexistaient - et qu'il ne faut pas idéaliser au prétexte qu'Indiens comme Mexicains se transforment au fil du temps en victimes. 


\section{NOTES}

1. . Le précédent ouvrait déjà de nouvelles pistes: Karl Jacoby, Crimes Against Nature. Squatters, Poachers, Thieves and the Hidden History of American Conservationism, Berkeley, University of California Press, 2001.

2. . http://brown.edu/Research/Aravaipa/index.html.

3. . Patricia N. Limerick, The Legacy of Conquest. The Unbroken Past of the American West, New York, Norton, 1987.

4. . Linda Gordon, The Great Arizona Orphan Abduction, Cambridge, Harvard University Press, 1999 ; Samuel Truett, Fugitive Landscapes. The Forgotten History of the U.S.Mexico Borderlands, New Haven, Yale University Press, 2006; Eric Meeks, Border Citizens. The Making of Indians, Mexicans and Anglos in Arizona, Austin, University of Texas Press, 2007 ; Katherine Benton-Cohen, Borderline Americans. Racial Divisions and Labor War in the Arizona Borderlands, Cambridge, Harvard University Press, 2009 ; Phylis Cancilla Martinelli, Undermining Race. Ethnic Identities in Arizona Miner Camps, 1880-1920, Tucson, University of Arizona Press, 2009. 